\title{
Systematic Study of Boron Determination by Graphite Furnace Atomic Absorption Spectrometry
}

\author{
R. Kobayashi, S. Okamura, K. Yamada and M. Kudo \\ Occupational Health Service Centre, Japan Industrial Safety and Health Association, 5-35-1, Shiba, \\ Tokyo 108, Japan
}

The optimized measurement of boron using graphite furnace atomic absorption spectrometry with a Zeeman effect background correction is described. Matrix modification and pretreatment. of graphite furnace were studied in an effort to improve the sensitivity and the elimination of memory effects. Based on this study, the tolerable ashing temperature was raised to $2100^{\circ} \mathrm{C}$ in the presence of matrix modifier, and the interferences from diverse elements were eliminated. The proposed method was applied for the determination of urinary boron. Recoveries of boron added to urine sample ranged from 95 to $98 \%$;relative standard deviation were within $10 \%$ at the $10 \mathrm{mg} / \mathrm{l}$ level. Boron contents determined by the proposed method ranged from $<1.0-7.7 \mathrm{mg} / 1$.

Keywords Boron, urine, graphite furnace atomic absorption spectrometry

Boron is a member of the group IIIB elements in the periodic table, to which aluminum and gallium also belong. The average boron content in crustal rock is $3 \times 10^{-4} \%$. Boron and its compounds are widely employed in the semiconductor industry and metallurgy. ${ }^{1}$ There are many reports on the determination of biological trace elements by inductively coupled argon plasma emission spectrometry ${ }^{2}$, and colorimetry ${ }^{3}$. However, most methods involve time-consuming sample treatment, with consequent risk of contamination. Although graphite furnace atomic absorption method offers a sensitive and precise method for the determination of traces elements in biological sample, the determination of boron by graphite furnace atomic absorption spectrometry has some problems, i.e., poor sensitivity, serious memory effect and shortened furnace lifetimes. One explanation for low sensitivity and serious memory effects is ascribed to the formation of non volatile refractory carbides. In this study, we proposed calcium-ascorbic acid modifier for the determination of boron, and applied to the proposed method to urine sample. It reduced background absorption due to inorganic salts matrices and enhance the sensitivity. The modifier allows direct determination of boron in urine by GFAAS.

\section{Experimental \\ Reagents and apparatus}

A boron standard solution and all matrix modifiers were purchased from a commercial source ( Wako Pure Chemical Industries, Ltd., 1000 ppm ). All solutions were prepared from analytical reagent grade chemicals and distilled water, and stored in polyethylene bottles.

A Hitachi Model Z-9000 zeeman atomic absorption spectrometer equipped with pyro-cuvette (Hitachi 180-7444) and a Perkin Elmer Model 5100 $\mathrm{ZL}$ atomic absorption spectrometer equipped with AS 40 autosampler were used for this investigation. The light source was a Hitachi hollow cathode lamp of boron.

Procedure

Urine was diluted $1+4$ with calcium-ascorbic acid. Forty $\mu$ l of the diluted urine was injected into the pyrolytically coated graphite tube The diluted urine 
was dried at $90-120^{\circ} \mathrm{C}$ for $40 \mathrm{sec}$, ashed at $3000^{\circ} \mathrm{C}$ for $15 \mathrm{sec}$ and $2200{ }^{\circ} \mathrm{C}$ for $3 \mathrm{sec}$, and atomized at $3000{ }^{\circ} \mathrm{C}$ for $20 \mathrm{sec}$. using "optical temperature control" and "carrier gas interrupt" modes. Finally, pyrolytically coated graphite tube was cleaned at $3000{ }^{\circ} \mathrm{C}$ for $20 \mathrm{sec}$. The absorption signal was recorded at $249.8 \mathrm{~nm}$ wavelength using a $0.4-\mathrm{nm}$ slit width, and the boron contents of the sample solution were determined by the method of standard additions.

\section{Results and Discussion \\ Selection of graphite tube}

The determination of boron with normal graphite tube causes several problems, e.g. poor sensitivity, serious memory effects. Therefore, a comparison was made among the sensitivities obtained with pyrolytically coated tube, L'vov platform, graphite tube, graphite cup and transversely heated graphite tube. The sensitivities of boron giving an absorbance of 0.0044 were listed in Table 1 . The sensitivity of pyrolytically coated tube in boron analysis were about $2.5,8.6,85.9$ and 37.5 times as high as that of L'vov platform, graphite tube, cup, and transversely heated graphite tube, respectively. From the comparison described above, the pyrolytically coated tube was selected for the present study.

Many papers have appeared that report long lifetime when the tubes were coated with the compounds that form metallic carbides on the graphite surface. ${ }^{4}$ Therefore, we tried to improve the life time of graphite fumace and the precision of boron determination using zirconium depositing on pyrolytically coated tubes as a solution, and firing with a furnace program. However, we found the zirconium coating of graphite furnace did not appear to be necessary.

Table 1 Comparison of various graphite furnace for boron measurement

\begin{tabular}{lcc}
\hline $\begin{array}{l}\text { Types of graphite } \\
\text { cuvvete }\end{array}$ & $\begin{array}{l}\text { Characteristic mass } \\
\text { (pg/0.0044A.S) }\end{array}$ & $\begin{array}{l}\text { Enhancement* } \\
\text { factor }\end{array}$ \\
\hline graphite cup & 1375 & 0.10 \\
pyro coated tube & 16 & 8.33 \\
$\begin{array}{l}\text { normal graphite } \\
\text { tube }\end{array}$ & 138 & - \\
$\begin{array}{l}\text { L'vov platform } \\
\begin{array}{l}\text { transversely } \\
\text { heated graphite } \\
\text { tube }\end{array}\end{array}$ & 40 & 3.44 \\
\hline
\end{tabular}

*Relative to normal graphite tube $=1.00$

\section{Selection of matrix modifier}

In order to select for a more suitable matrix modifier for the determination of boron, the stabilizing effects of aluminum, barium, calcium, nickel, zirconium, zirconium-nickel and calciumascorbic acid, have been investigated. The signal of boron increased in the following order ; Ca-ascorbic acid $>\mathrm{Zr}-\mathrm{Ni}=\mathrm{Ca}>\mathrm{Ba}>\mathrm{Al}$. Among these matrix modifiers examined in this study, calcium-ascorbic acid is the best for boron sensitivities of all. In addition to this, the calcium-ascorbic acid modifier reduce the reproducibility, of boron analysis more than that of the other matrix modifiers.

Table 2 Maximum temperature loss free thermal pretreatment of boron determination

\begin{tabular}{|c|c|c|c|c|c|c|}
\hline & none & Al & $\mathrm{Ba}$ & $\mathrm{Ca}$ & $\mathrm{Zr}-\mathrm{Ni}$ & $\begin{array}{l}\text { Ca- } \\
\text { Asc. }\end{array}$ \\
\hline $\begin{array}{l}\text { Opt. ash } \\
\text { temp. }{ }^{\circ} \mathrm{C}\end{array}$ & $\begin{array}{l}300 \sim \\
1300\end{array}$ & $\begin{array}{l}600 \sim \\
2200\end{array}$ & $\begin{array}{l}700- \\
2200\end{array}$ & $\begin{array}{l}1300 \\
1500\end{array}$ & $\begin{array}{l}500 \\
2200\end{array}$ & $\begin{array}{l}1000 \sim \\
2200\end{array}$ \\
\hline $\begin{array}{l}\text { Enhancement } \\
\text { factor }\end{array}$ & $\cdot$ & 2.2 & 1.6 & 3.0 & 3.0 & 4.8 \\
\hline
\end{tabular}

*Relative to no modifier $=1.00$

Furnace parameters

The performance of the graphite furnace for boron determinations was investigated. The effects of ashing and atomization temperature on the absorbance of boron in the presence of calciumascorbic acid, and zirconium-nickel were shown in Fig. 1. When calcium-ascorbic acid, and zirconiumnickel were used for the matrix modifier, the highest permissible ashing temperature was raised to $2200^{\circ} \mathrm{C}$, and the sensitivities for the determination of boron was improved by a factor of 1.7 over that in the absence of matrix modifier. However, zirconiumnickel modifier gave unstable signals and the effects of the ashing temperature showed complex pattern. This experimental results indicated that the use of zirconium-nickel modifier have the possibility to cause a problem in quality control of the boron analysis. In contrast, stabilizing and highest atomization peak was observed when the mixture of calcium-ascorbic modifier was used. In addition to this, it was necessary to clean graphite furnace at $3000^{\circ} \mathrm{C}$ for $20 \mathrm{sec}$ for the elimination of serious memory effect. From these results, an ashing temperature of $2200^{\circ} \mathrm{C}$, atomization temperature of $3000{ }^{\circ} \mathrm{C}$ for $20 \mathrm{sec}$ and cleaning temperature of $3000{ }^{\circ} \mathrm{C}$ for $20 \mathrm{sec}$ were selected for urinary boron analysis. 


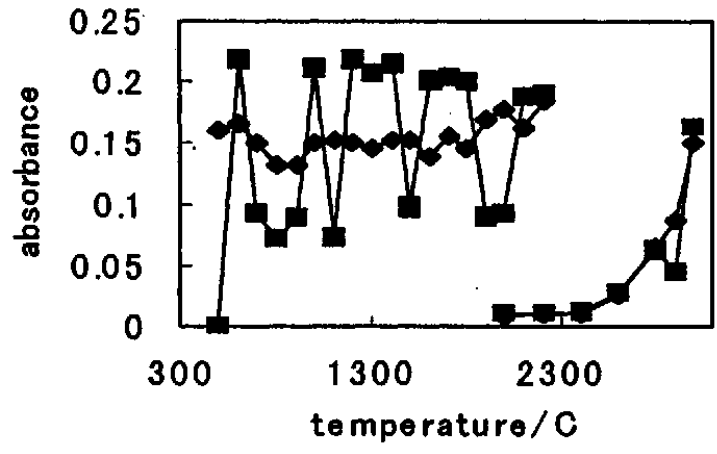

Fig.1 Effects of graphite furnace temperature on boron absorbance

$$
\rightarrow-\mathrm{Ca}+\mathrm{asc} . \rightarrow-\mathrm{Zr} / \mathrm{Ni}
$$

\section{Effects of the ashing time}

Byrne has been reported that the formation of the carbide of boron is more than $2000{ }^{\circ} \mathrm{C}$ from the thermodynamics calculation. In addition to this, it happens about the evaporation loss below $2000^{\circ} \mathrm{C}^{5}$ because of the formation of boron oxide. Therefore, it was necessary to shorten ashing time to prevent volatile boron which did not form the boron carbide from running away from the graphite furnace to raise the sensitivity of boron. Figure 2 shows the relation between ashing time and sensitivity. The absorbance of boron shows the maximum value for three seconds or less at the ashing stage.

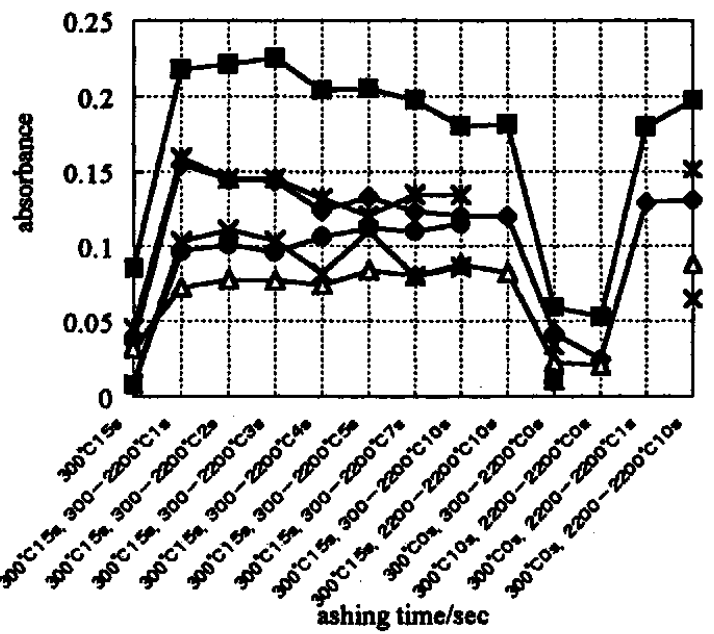

Fig.2. Effect of ashing time on boron absorbance of graphite furnace atomic absorption spectrometry

\begin{tabular}{ll}
$\longrightarrow \mathrm{Ca}$ & $\rightarrow \mathrm{Ca}+$ asc. \\
$\rightarrow-\mathrm{Ba}$ & $\rightarrow-\mathrm{Al}$ \\
$\rightarrow-\mathrm{Zr} / \mathrm{Ni}$ & $\rightarrow-\mathrm{Ca}+$ asc.+Urine \\
\hline
\end{tabular}

\section{Effects of sample volume}

The sensitivity and reproducibility of graphite furnace atomic absorption analysis of boron are depend on the sample injection volume. The sensitivity and reproducibility improved with increasing volume. More than $30 \mu \mathrm{l}$ injection of sample solution, the sensitivity was enhanced 4 times higher than that of $10 \mu \mathrm{l}$ injection and the coefficient of variation was improved less than $10 \%$.

Effects of foreign ions

The effects of foreign ions on the graphite furnace atomization of boron, were studied. The concentrations of foreign ions in this study were comparable to those that may be found in the urine used in the procedure. Table 3 shows the effects of negative errors of $29-99 \%$, when they coexisted with boron at the levels found in the urine sample. However, the results of recovery tests added to urine samples indicated that boron recoveries ranged from $95-98 \%$. It is assumed that the urinary interfering constituents are compensated each other.

Table 3 Comparison of Interference effects in determination of boron in the presence of calcium ascorbic acid modifier

\begin{tabular}{|c|c|c|c|c|}
\hline $\begin{array}{l}\text { Interfer } \\
\text {-ent }\end{array}$ & $\begin{array}{l}\text { Conc.of } \\
\text { matrices } \\
\left(\mathrm{mg} \mathrm{ml}^{-1}\right)\end{array}$ & $\begin{array}{l}\text { Present } \\
\text { in urine } \\
\left(\mathrm{mg} \mathrm{ml}^{-1}\right)\end{array}$ & $\begin{array}{l}\text { Relative } \\
\text { absorbance } \\
\text { of boron } \\
1000 \mathrm{C}^{\circ}\end{array}$ & $1500 \mathrm{C}^{\circ}$ \\
\hline None & - & - & 1.00 & 1.00 \\
\hline $\begin{array}{l}\mathrm{K}+ \\
\mathrm{Na}+\end{array}$ & $\begin{array}{r}1.0 \\
10.0\end{array}$ & $\begin{array}{l}0.75 \\
1.31\end{array}$ & $\begin{array}{l}0.56 \\
0.35\end{array}$ & $\begin{array}{l}0.71 \\
0.85\end{array}$ \\
\hline $\mathrm{Mg}^{2+}$ & 0.1 & 0.032 & 0.57 & 0.84 \\
\hline $\mathrm{Al}^{3+}$ & 1.0 & 1.0 & 0.70 & 1.03 \\
\hline $\mathrm{Cl}^{-}$ & 1.0 & 2.2 & 0.57 & 1.06 \\
\hline $\mathrm{SO}_{4}{ }^{2-}$ & 1.0 & 0.65 & 0.05 & 0.38 \\
\hline
\end{tabular}

Accuracy of graphite furnace method in urinary boron,

To check the accuracy of the direct determination of boron in urine by GFAAS, the comparison between the standard addition method and the calibration curve method was studied. As a results of chemical interference due to the urine matrices, the slope of the standard addition plots differed from that of the calibration curve. Standard addition method was applied to ten normal urine samples and we knew similar enhancement relative to the aqueous curve. Chemical matrices in urine samples vary considerably and matrix matching would be impossible. Therefore, the method of standard additions was recommended for the determination of boron in urine. 


\section{Recovery test}

In order to investigate the applicability of the proposed method to urine samples, the recovery of known amounts of boron added to urine samples was examined. The amounts of boron, added were 0.99 and $1.96 \mu \mathrm{g}$. The recoveries obtained by the standard addition method ranged 95 to $98 \%$, and the relative standard deviation (five replicate samples) was within $10 \%$ at the $5 \mathrm{mg} \mathrm{l}^{-1}$. These values were sufficient for the determination of trace elements in urine.

Table 3 Recovery of boron added to urine sample* using GFAAS

\begin{tabular}{lccc}
\hline method & added $/ \mu \mathrm{g}$ & found $/ \mu \mathrm{g}$ & Recovery $\%$ \\
\hline standard & 0 & 0 & - \\
addition & 0.99 & 0.94 & 95.0 \\
& 1.96 & 1.92 & 98.1 \\
\hline
\end{tabular}

*Urine's were diluted $1+1$ with $\mathrm{Ca}$ and ascorbic acid.

Detection limits

The limits of detection were $24 \mathrm{ng}$ for boron, defined as twice the standard deviations of the procedural blank signals $(n=3)$. It can be seen that "normal" level in urine of boron, should be detectable.

Results of analysis

As quantitative recoveries were obtained, the recommended method was applied to the determination of boron in a number of urine samples.

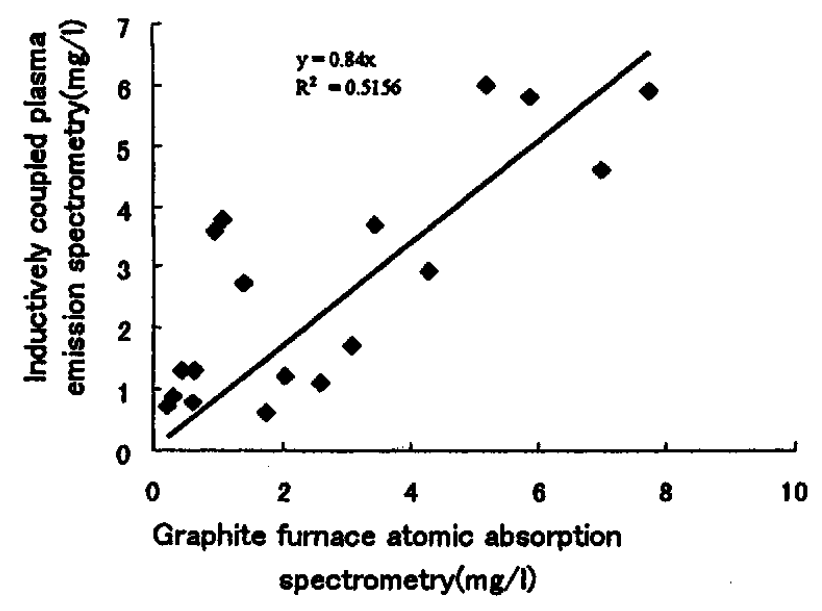

Fig.3 Relation between boron analytical results between graphite furnace atomic absorption spectrometry and inductively coupled plasma emission spectrometry

The analytical results for boron content of eighteen urine samples from unexposed persons, as determined by the graphite furnace method and inductively coupled plasma argon plasma emission spectrometry are given in Fig. 3. The urinary boron contents in the present study ranged from $<1$ to $7.7 \mathrm{mgl}^{-1}$. These values were high about two order of magnitude above than that of germanium which also belongs to group III $B$ elements and are almost same as the values reported before. ${ }^{6}$ However, the agreements were good at high concentrations, but less satisfactory at lower concentrations. This may be the result of carbon-boron interference's at low concentration

Comparative study

The comparison of the direct GFAAS and ICPAES is shown in Table 4. In direct graphite furnace method, the recoveries of boron added to urine sample were sufficient for the accurate determination. However, the detection limits of the GFAAS were one order of magnitude lower than that of the ICPAES method. In addition to this, compared with the ICP-AES, the advantages of the GFAAS are to be able to reduce operation-steps and that an amount of the sample necessary for the analysis can be less than that of ICP-AES. On the other hand, the defect of GFAAS is that the variation of analytical results in the low concentration region is not good.

Table 4 Comparison of GFAAS with one-drop ICP -AES for the analysis of urinary boron

\begin{tabular}{lcc}
\hline method & GFAAS & ICP-AES \\
\hline Sample volume/ml & 0.1 & 5 \\
Detection limits/ $\mu$ g/1 & 1 & 0.1 \\
Recovery of B added to & $95.0-$ & $96.0-101$ \\
urine, \% & 98.1 & \\
Time required/min & 30 & 2 \\
\hline
\end{tabular}

\section{Reference}

(1) I.L.O., "Encyclopedia of Occupational Health and Safety", vol.I, pp.319, International Labor Office, Geneva(1972).

(2) M.W.Pritchard and J.Lee, Analytica Chimica Acta,157,313-326(1984)

(3) A.S.Baker, J.Agric.Food.Chem.,12,367(1964).

(4) M.Laguera, Y.Madrid and .C.Camara, Anal. At. Spectrom. 6, 669(1991).

(5) W.Frech,A.Cedergren and E.Lundberg, Analyrtik treffen Abstracts, p.102, 8-12, Nov., Neubrandenburg, F.R.G.(1982).

(6) G. V. Iyengar, W. E. Kollmer and H. J. M. Bowen, The Elemental Composition of Human Tissues and Body Fluids" p.124, Verlag Chemie, New York, 1978. 